\title{
JUDICIALIZAÇÃO DA SAÚDE: DIREITOS E CONSEQUÊNCIAS
}

\author{
JOSÉ CECHIN ${ }^{1}$
}

\section{INTRODUÇÃO}

Planos e seguros de saúde seguem princípios similares aos dos seguros gerais. Asseguram serviços de assistência à saúde ou reparação (parcial ou total) dos gastos dos tratamentos, mediante o pagamento de um "prêmio", ou contraprestação pecuniária ou ainda simplesmente mensalidade, ao operador do plano. Estão cobertos eventos futuros e incertos, que podem acarretar perdas patrimoniais à pessoa ou família segurada. Em saúde, esses eventos futuros e incertos são tipicamente o adoecimento. $\mathrm{O}$ financiamento dos planos baseia-se no princípio do mutualismo, em que todos contribuem com seus prêmios para um fundo comum do qual se retiram os recursos para custear os tratamentos daqueles segurados que têm o infortúnio de adoecerem.

À operadora cabe organizar o mútuo, equacionar o financiamento, fixar os prêmios com base em cálculos atuariais, realizar as cobranças, organizar a rede prestadora dos serviços de assistência à saúde e fazer os pagamentos devidos. Nota-se que os recursos das operadoras se originam dos pagamentos dos contratantes de planos e seguros de saúde. Seus recursos não têm outra origem. Mesmo as eventuais rendas financeiras resultam do acúmulo de resultados de exercícios anteriores que tiveram origem nas mensalidades.

Para que a operação seja viável é necessário que seja economicamente rentável. Para reduzir risco de operações não rentáveis, a operadora, por decisão do órgão regulador, a Agência Nacional de Saúde Suplementar, ANS, deve apresentar a Nota Técnica de Registro de Produto, NTRP, com a demonstração dessa viabilidade, discriminando a estruturação das mensalidades por faixas etárias, o preço de cada faixa e os respectivos percentuais de reajuste. Essa Nota Técnica estabelece os parâmetros para o equilíbrio econômico-financeiro do plano, que devem permanecer no tempo. Aprovada a NTPR, a operadora pode iniciar a comercialização de planos, adotando com preço um valor dentro da faixa de mais $30 \%$ ou menos $30 \%$ do valor médio nela justificado.

A estruturação dos preços por faixa etária segue princípios do seguro segundo os quais o grupo coberto deve ter riscos semelhantes, que no caso da saúde equivale ao custo médio per capita dos serviços de saúde consumidos pelo grupo. Como é bem sabido, esse custo médio varia consideravelmente com a idade. Preço uniforme em todo o grupo independente de idade, que deve corresponder ao custo médio per capita de toda a população alvo do plano, tenderia a afastar os jovens, de baixo risco, e atrair os mais idosos, de mais alto risco. O custo médio do grupo participante seria mais alto, afastando ainda mais os jovens e concentrando a

\footnotetext{
${ }^{1}$ Superintendente Executivo do Instituto de Estudos de saúde Suplementar - IESS. Foi Ministro de Estado da Previdência e Assistência Social do Governo de Fernando Henrique Cardoso.
} 
seleção nos mais idosos, elevando ainda mais o custo médio. Esse processo em espiral terminaria por concentrar no plano os indivíduos de maior custo percebido.

Para manter o equilíbrio econômico-financeiro no tempo, os planos são reajustados anualmente para compensar as variações dos preços que impactam a prestação dos serviços e as variações na frequência de utilização dos serviços, pois que ambos afetam as despesas e suas variações. Os reajustes anuais devem recompor o equilíbrio econômico-financeiro do plano. Além desse reajuste anual, os beneficiários dos planos também podem ter outro reajuste, por mudança de faixa etária, tendo em cada mudança de faixa etária dois reajustes no ano.

Os planos individuais e familiares têm seu reajuste anual máximo determinado pelo Governo. Já os planos coletivos não têm esse limite. Planos coletivos com mais de trinta vidas têm seu reajuste anual determinado por livre negociação entre as operadoras e o contratante ou estipulante do plano. Os contratos com menos de trinta vidas que estejam na mesma operadora são tratados como um único pool de risco e todos têm o mesmo percentual de reajuste, que deve ser aderente à variação média anual da despesa com serviços de assistência à saúde desse grupo. Obviamente, o percentual varia de operadora para operadora. $\mathrm{O}$ órgão regulador desejou com essa medida evitar que alguns contratos tenham reajuste anual muito alto em razão de alguns de seus participantes terem tido enfermidades graves.

Essas são as principais características dos planos e seguros de saúde que interessam para este artigo. As próximas seções tratam da necessidade de regulação desse setor e seus efeitos no mercado, as tendências da judicialização, suas condições de contorno, os principais motivos das demandas e as consequências econômicas e comportamentais das decisões.

\section{REGULAÇÃO NECESSÁRIA}

A necessidade da regulação na saúde está bem estabelecida na literatura da economia da saúde e as razões ligam-se a imperfeições no mercado, essencialmente a notória assimetria de informação. Alguns exemplos ilustram a situação. $O$ consumidor que busca um plano de saúde conhece seu estado de saúde com muito maior precisão do que a seguradora; assimetria semelhante se observa entre o paciente que melhor conhece seus sintomas do que seu médico; este por sua vez tem maior conhecimento para realizar o diagnóstico e prescrever conduta de recuperação. Pode-se ainda alegar que os serviços de saúde são meritórios e sua oferta não deveria ser deixada exclusivamente ao mercado, ou que o consumidor é hipossuficiente frente à operadora. Todos esses argumentos apontam para a necessidade de regulação desse mercado de saúde. Observe-se que a regulação objetiva superar ou reduzir essas imperfeições de mercado; regras que não cumpram com esse objetivo são supérfluas quando não positivamente negativas.

Os planos de saúde iniciaram seu desenvolvimento no Brasil por ocasião do plano de Metas do Governo Juscelino Kubitschek, que incentivou a industrialização do País. Tratava-se de permitir aos funcionários das montadoras automobilísticas o acesso mais rápido e resolutivo aos serviços de saúde, que contaram com 
incentivos do Governo pois auxiliavam aos então Institutos de Aposentadoria e Pensões na oferta de serviços de saúde aos brasileiros.

Durante décadas os planos funcionaram sem regulação, à exceção dos seguros saúde, operados por empresas seguradoras a partir da década de 1980, que estavam sujeitos à regulação da SUSEP. O mercado se expandiu tanto em termos de número de operadoras quanto de beneficiários, especialmente na primeira metade da década de 1990, em meio à hiperinflação reinante na sociedade brasileira. E as reclamações também.

A ausência de regulação permitia abusos de diversas ordens, como nas carências sem regras e excepcionalmente longas. Tampouco havia regras para abertura e funcionamento de operadoras; exigências para constituição de provisões e reserva; avaliações atuariais para justificação de preços; entre outras.

A regulação veio com a Lei 9.686/98, modificada no primeiro dia de sua vigência e mensalmente por mais 44 Medidas Provisórias. Essa Lei já completou 21 anos e é chegada a hora de sua atualização às profundas mudanças que aconteceram na sociedade nessas duas décadas.

A Lei teve importantes efeitos, que podem ser resumidos no aperfeiçoamento do mercado, expresso na maior confiabilidade tanto para compradores de planos quanto para as operadoras. A Lei trouxe três eixos de regulação: Administrativa, Econômico-financeira e Assistencial. No eixo Administrativo, cuidou a Lei de estabelecer regras de acesso, autorização de funcionamento, registro de produto, quebra de contrato individual pela operadora, liquidação extrajudicial e processo sancionador. No Econômico-financeiro, estabeleceu regras de solvência, a exigência de reservas e constituição de ativos garantidores, plano de contas, autorização dos reajustes dos planos individuais, responsabilização dos administradores, entre outras. Na Assistencial, estabeleceu os grandes tipos de cobertura, fixou prazos máximos para as carências e a cobertura de todas as doenças da CID-10, atribuiu ao órgão regulador a competência para definir a lista de procedimentos de cobertura mínima obrigatória (denominada de Rol de Procedimentos), listou as exclusões de coberturas, as formas de cobertura para doenças e lesões preexistentes (entendidas como aquelas de que o consumidor tinha conhecimento na assinatura do contrato do plano), os períodos máximos de carência, as condições de alteração a rede prestadora de serviços de assistência à saúde. Importante assinalar que a Lei vedou limites de atendimento, tetos de valor e seleção de risco.

Dessa descrição fica fácil entender por que a Lei aperfeiçoou o mercado, tornando-o mais confiável para todos. Ao padronizar os tipos de planos e coberturas, facilitou sua comercialização tanto para os consumidores quanto para as operadoras. Teve, no entanto, um problema: dificultou a idealização de novos produtos por parte das operadoras e restringiu o leque de escolhas por parte dos consumidores. Decorridos mais de 20 anos de sua edição, é chegado o momento de sua revisão, até para levantar essa restrição apontada. Em suma, trata-se de permitir o desenho de produtos mais próximos dos desejos e possibilidades econômicas da população desejosa de ter plano de saúde. 
Para evitar mal-entendidos, trata-se de acrescentar produtos na lista em oferta e, portanto, mais escolhas por parte dos consumidores. Ampliar o leque de escolhas de produtos não equivale a restringir direitos dos consumidores, antes o contrário, com maior leque de escolhas ficam ampliados os direitos dos consumidores. Cada qual escolhe de acordo com suas aspirações e possibilidades.

\section{TENDÊNCIAS DA JUDICIALIZAÇÃO}

Judicialização se refere ao crescimento acelerado do número de demandas judiciais na saúde pública em relação à população ou ao orçamento do SUS, ou, na privada, em relação ao número de beneficiários ou às receitas das mensalidades ou ainda às despesas com assistência à saúde. $\mathrm{O}$ artigo explora essa tendência, seus promotores e consequências.

O filósofo italiano Norberto Bobbio descreve a era atual como a Era dos Direitos, em contraposição a eras anteriores em que os indivíduos, normalmente súditos em algum reinado ou império, tinham deveres, especialmente para com o Estado, mas poucos direitos. Perante o Estado, os deveres das pessoas estavam estabelecidos nas constituições, nas leis e normas, entre eles figurava o dever de pagar tributos. Pouco se falava dos direitos, que foram sendo conquistados ou reconhecidos no processo de desenvolvimento. Nesse processo evolutivo, passou-se dos Diretos à vida e à liberdade, para os direitos à saúde e educação, à dignidade e ao exercício das preferências individuais quanto crenças, religião, valorização do gênero, à participação em sociedade e à não discriminação de qualquer espécie. Entende-se claramente que a era dos direitos para o filósofo representa inegavelmente um importante avanço social.

Na época atual, a consciência dos direitos cresceu entre todas as pessoas, assim como o desejo de tê-los satisfeitos. E isso é bom. No entanto, parece que esse sentimento relativo aos direitos individuais termina por obscurecer que também há deveres como contrapartida de cada direito. Reconhecer deveres não significa postular uma volta ao passado, um retrocesso às eras medievais, feudalistas, escravagistas ou mesmo dos primórdios do capitalismo. Bem-vindos todos os direitos, mas sem olvidar que os indivíduos também carregam consigo uma gama de deveres. Nunca é demais exaltar os direitos individuais e sociais, mas essa exaltação não deve obscurecer o reconhecimento dos deveres.

A crescente conscientização dos direitos, junto com a maior facilidade de demandá-los e de acesso à Justiça, vem levando ao que se denomina de judicialização - o aumento acelerado do número de demandas judiciais. Esse fenômeno acontece em diferentes sociedades, em diferentes setores da atividade humana, nos negócios privados e na política, e especialmente na área da saúde, pública e privada.

No entanto, a merecida ênfase nos direitos parece estar levando indivíduos a somente verem os direitos e a não verem limites em seus direitos. Em saúde, essa questão assume uma grande importância, por vezes baseada nos conceitos de vida e saúde como bens supremos, indisponíveis até mesmo para os indivíduos. As 
demandas em saúde não conhecem limites, como testemunha o crescimento acelerado das ações judiciais - 130\% entre 2008 e 2017, comparado com 50\% de aumento na Justiça com o um todo. ${ }^{2}$

O número de demandas judiciais na saúde pública e privada é contado em diversas centenas de milhares. ${ }^{3}$ Cresceu de forma intensa, até mesmo depois de 2014, com a forte redução do número de beneficiários de planos de saúde - perda de 3,6 milhões de vínculos entre 2014 e 2017. Muitas ações buscam a efetivação do direito descumprido, e nesses casos, cabe apenar o infrator, para inibir que a prática seja repetida e se alastre. Mas também se observam muitos diversos casos em que os demandantes "buscam vantagens" individuais não asseguradas nas normas vigentes ou nos contratos. Como tratar casos desse tipo? Quais as consequências do deferimento dessas demandas? Essas questões serão abordadas mais adiante.

Utiliza-se a expressão "busca de vantagem" porque, em tais situações, não houve o cumprimento do dever associado - que no caso da saúde privada é o pagamento do prêmio ou mensalidade correspondente do plano de saúde; no caso do SUS, o acesso a procedimento ou medicação não incluídos nas suas listas, na tentativa de obter o que não está disponível para todos. Uma vantagem obtida individualmente onera toda a mutualidade do plano de saúde e toda a população que precisa recorrer ao SUS. Por isso, enfatiza-se, a era dos direitos deveria vir acompanhada da era dos deveres - não somente para com o Estado, como tradicionalmente, mas também, e de forma mais ampla, para com mutualidades e toda a sociedade.

Em suma, direitos e deveres devem ser indissociáveis. $\mathrm{O}$ direito à saúde, usualmente entendido como o direito de acesso aos procedimentos de diagnóstico e terapias sempre que a saúde faltar, deveria pressupor o cumprimento de deveres, como o dever de contribuir (com a mensalidade do plano ou com os tributos que financiam a Seguridade Social) e até mesmo os deveres de cuidar da própria saúde pela adoção de hábitos saudáveis. ${ }^{4}$

\footnotetext{
${ }^{2}$ Dados da Pesquisa do INSPER para o CNJ 2019: “Justiça Pesquisa: Judicialização da Saúde no Brasil: Perfil das demandas, causas e Propostas de Solução". O trabalho identificou 499 mil processos na Primeira Instância e 277 mil na segunda instância.

${ }^{3}$ Segundo o estudo do INSPER, número de processos distribuídos na primeira instância passou de 27 mil em 2010 e 2011 para 96 mil em 2017; na segunda instância, de 27 mil para 41 mil.

${ }^{4}$ A reforma de 2013 da Constituição do NHS incluiu dispositivos tratando das responsabilidades do cidadão britânico, entre elas o de cuidar de sua saúde. Veja-se a este respeito proposta do Select Committee on the Long Term Sustainability, da Câmara dos Lordes do Reino Unido: "320. The Government should be clear with the public that access to the NHS involves patient responsibilities as well as patient rights. The NHS Constitution should be redrafted with a greater emphasis on these often-overlooked individual responsibilities. The Government should relaunch the Constitution as part of a renewed and sustained drive to improve health literacy and educate the public about their common duty to support the sustainability of the health service, with children, young people, schools, colleges, further education institutions and employers forming a major part of this initiative."

Fonte: https://publications.parliament.uk/pa/ld201617/ldselect/ldnhssus/151/15109.htm.
} 
Houve-se com frequência que a decisão de uma demanda sobre saúde não deve ser fria, sem compaixão, a adstrita aos termos explícitos das leis e normas nem resultar de avaliações matemático-atuariais que sempre insensíveis. Será difícil embutir sentimentos no cálculo matemático-atuarial, mas nem por isso deve-se entender que os profissionais dessas áreas sejam desprovidos de sentimentos e compaixão. Cada coisa no seu lugar.

A crescente judicialização traz custos elevados para toda a sociedade, que poderiam ser evitados. Para enfrentar esse crescimento deve-se considerar a judicialização devida sempre que um direito legítimo é desrespeitado, e separar daquela que busca uma vantagem individual. Para o primeiro caso, devem-se aperfeiçoar as normas, eliminando lacunas e imperfeições. E os ofensores devem se reequipar para oferecer a solução adequada e tempestiva a seus segurados. Para o segundo caso, as decisões devem considerar as consequências econômicas do Direito, tema que vem ganhando relevância em todo mundo. É bem possível que uma decisão, aplicada a um indivíduo identificado, por compaixão ou justiça social ou favorecimento do lado mais fraco da relação, possa ser cumprida sem maiores efeitos econômico-financeiros. Todavia, sua extensão a todos os indivíduos que estiverem nas mesmas situações, mediante pleitos semelhantes, pode se mostrar economicamente inviável. Portanto, é essencial avaliar as consequências econômicas do direito, tendência essa em curso em diversas sociedades.

$\mathrm{Na}$ próxima seção trata-se da análise das condições de contorno da judicialização.

\section{O CONTEXTO DA CRESCENTE JUDICIALIZAÇÃO}

$\mathrm{O}$ atual contexto socioeconômico e cultural favorece o movimento de reivindicação dos direitos. A forte intensificação das propensões a reivindicar deriva da maior consciência dos direitos. Resulta de uma profunda mudança cultural na sociedade, iniciada com a publicação do Código de Defesa do Consumidor, em 1990. Bem-vinda essa mudança.

Não há que se tolerar qualquer desrespeito a direitos. Outra deve ser a atitude relativamente a tentativas de obter vantagens não asseguradas nas normas ou nos contratos nem justificadas socialmente.

Testemunham-se rápidas transformações de toda a ordem no mundo tecnológicas, sociais, culturais, de costumes. Em tecnologia, o ritmo das inovações não conhece precedentes na história. Produzem-se tecnologias dispendiosas em velocidade superior ao crescimento econômico e, portanto, às possibilidades econômico-financeiras das famílias e seus orçamentos domésticos, das empresas, dos orçamentos públicos. A prolongada crise econômica no Brasil acrescenta dificuldades a todos esses setores, enquanto a epidemiologia segue seu curso normal ou até enfrenta agravamentos devido ao stress provocado por situações de crise.

A tecnologia da informação permite a difusão virtualmente instantânea das inovações produzidas em qualquer parte do globo, o que exacerba as aspirações na 
sociedade brasileira, mas não acrescenta renda às pessoas e famílias. A incorporação das inovações não é, nem pode ser, simultânea à incorporação em outras sociedades mais desenvolvidas. A aspiração assim incentivada leva os indivíduos a demandarem acesso imediato às últimas inovações, muitas vezes ainda sem suficiente evidência de sua efetividade.

Motivados pela percepção dominante, nem sempre correta, de que o mais caro e mais recente é sempre melhor, os consumidores saem à busca, inclusive pela via judicial, de acesso a essas inovações. Tendência essa particularmente intensa em uma sociedade que privilegia o inédito, o consumo, o mais sofisticado, mesmo sem evidências de sua efetividade ou de melhores resultados clínicos para os pacientes.

Estimula a demanda judicial a visão prevalecente entre beneficiários, operadores do direito, magistrados, profissionais de saúde, de que o acesso às tecnologias médicas não deve encontrar limites e todos os procedimentos inventados para todas as doenças devem estar ao alcance das pessoas, independentemente de deveres de contribuição. Ou mesmo, independentemente de evidências de efetividade de tais tecnologias. A falta de transparência nos métodos de incorporação gera desconhecimento, o que também enseja demandas por parte dos consumidores e dificuldade de entendimento tanto pelos magistrados como pela população.

Por vezes, defende-se até mesmo as tecnologias ainda experimentais ou a utilização off label, para as não se acumularam ainda evidências suficientes de sua eficácia e efetividade. Colaboram ainda para o crescimento das demandas a atitude de profissionais diante de inovações recém-lançadas no mundo, ainda sem evidências firmes de sua efetividade clínica, de testá-las em seus pacientes, muitas vezes desesperados diante do mal que os aflige.

A insuficiência de conhecimento ou entendimento das técnicas atuariais, das normas, dos textos dos contratos e dos conceitos do mutualismo em que se baseiam os planos de saúde motiva demandas inapropriadas, ainda que de boa-fé. A matéria é tecnicamente complexa e de difícil entendimento e sua superação exigiria incluí-la nos currículos educacionais dos diferentes níveis de educação.

No setor de saúde, os mercados são notoriamente imperfeitos, como notado na introdução, sendo a assimetria de informação a principal delas. Demandas que chegam à Justiça são sempre acompanhadas de um laudo técnico de um profissional da saúde, atestando a necessidade, sob pena de graves consequências à saúde do paciente. O magistrado, que não tem formação técnica em medicina, se julga incompetente para avaliar o laudo médico e tende a acatar a demanda. Conhecedor desse problema, o CNJ adotou diversas iniciativas como o intuito de colocar à disposição dos Juízes meios para que busquem informações relativas ao laudo. Entre elas, a criação de Núcleos de Apoio Técnico, bibliotecas de pareceres e notas técnicas. A consulta a esses meios permite que o magistrado forme sua convicção quanto à questão de se tratar de emergência ou não, se há alternativas disponíveis, se o procedimento indicado é compatível com as evidências clínicas. 
O CNJ tem sido incansável em estimular os Juízes a consultarem a esses dispositivos e assim prolatarem decisões mais bem fundamentadas.

Não obstante os esforços do $\mathrm{CNJ}$ pesquisas recentes mostraram que os julgadores faziam pouco uso desses meios ${ }^{5}$. O mesmo comportamento ainda era observado em pesquisas mais recentes, como o Relatório do TCU 6 de 2017 e a pesquisa feita pelo INSPER para o CNJ de 2019. Diante dessas constatações, o CNJ não apenas reiterou suas recomendações, como, para torná-las mais facilmente exequíveis, estabeleceu cooperações técnicas com importantes instituições de saúde e acadêmicas para desenvolverem bibliotecas e pareceres para serem consultados pelos magistrados.

Também estimula as demandas judiciais, como apontado em Relatório do TCU, o percentual de decisões favoráveis aos demandantes, de mais de $70 \%$. O consumidor, ciente dessa estatística, se sentirá incentivado a demandar, mesmo que sua demanda não tenha bons fundamentos. Decisões favoráveis aos demandantes resultam da visão adotada por Juízes de favorecimento à parte menos privilegiada ou hipossuficiente na relação com a operadora ou com o Estado, ao sopesamento da função social do contrato, e da Justiça caritativa. Em que pese a relevância desses argumentos, não cabe ao Juiz, argumenta LRB, mas sim ao Legislador, estabelecer a política de assistência social e ao Juiz, de fazer cumprir a Política fixada em Lei. Observa-se uma tendência entre magistrados de diferentes regiões do mundo, de basear suas decisões no chamado "principismo", ponderando princípios constitucionais como o valor supremo da vida, o direito fundamental à saúde, a dignidade da pessoa humana.

Não se trata, em absoluto, de negar validade a esses argumentos, mas de direcionar sua invocação em situações específicas. Como é notória, as normas são gerais, mas a realidade nem sempre se encaixa perfeitamente nos seus ditames. Esses princípios podem, e devem, ser invocados para os casos típico de decisão dos Juízes, em que não é óbvio, a priori, a quem assiste o direito. A invocação de princípios para a formação da decisão nesses casos é apropriada. Todavia, sua invocação em outros casos pode gerar incertezas jurídicas que não devem interessar a ninguém.

\section{PRINCIPAIS MOTIVADORES DAS DEMANDAS JUDICIAIS}

Em fins de 2019, tramitavam na Justiça mais de 670 mil demandas contra planos e seguros de saúde. ${ }^{7}$ Os motivadores objetivos das demandas se vinculam a diversos fatores típicos do setor de saúde. O setor operou durante quase meio século, desde sua criação em meados dos anos 1950 até a Lei 9.656, de 1998, sem regulamentação (exceção feitas às seguradoras que entraram nesse mercado nos anos 1980, submetidas à regulamentação da SUSEP). Os contratos de planos e

\footnotetext{
${ }^{5}$ Neto, J. P. G. e Schulze, C. J. Direito à Saúde. Análise à Luz da Judicialização. PA: Verbo Jurídico, 2015. ${ }^{6}$ TCU - Relatório de Auditoria Operacional na Saúde Pública. 16 de agosto de 2017.

7 Informação fornecida por C. Schulze no curso à distância a ser veiculado pela Escola de Magistratura de Tocantins.
} 
seguros de saúde pactuados no período anterior à eficácia da Lei 9.656/98, eram muito heterogêneos quanto às diferentes cláusulas relativas às carências, coberturas e exclusões, limites financeiros, de tempos de internação, de número máximo de determinados. Essa enorme heterogeneidade de cláusulas foi resolvida com a Lei 9.656/98 normatizou esses e outros aspectos, como visto acima nesse texto.

A regulamentação determinava a migração ou adaptação dos contratos anteriores a 1 de janeiro de 1999, ditos contratos ou planos antigos, às determinações da lei. Essa determinação foi contestada pelos consumidores, que preferiram manter seus contratos a ter que arcar com majoração das mensalidades. Com essa escolha, as limitações de seus contratos antigos continuavam válidas, para insatisfação daqueles beneficiários que vinham a necessitar de coberturas incluídas na nova regulamentação, mas excluídas de seus contratos. As demandas típicas nessas situações eram contra limites financeiros, reajustes e exclusões de cobertura.

Vários desses motivadores foram resolvidos com o Código de Defesa do Consumidor, que declara nulas de pleno direito cláusulas limitadoras, normalmente escritas para não serem facilmente percebidas, de coberturas excluídas, gastos financeiros, tempos de internação, número de procedimentos, entre outras.

Com exceção das cláusulas consideradas nulas pelo Código de Defesa do Consumidor, os termos desses contratos antigos constituíam atos jurídicos perfeitos, pois não contrariavam nenhuma norma legal, porque tal norma não existia.

Não havia norma para os reajustes anuais e cada contrato podia explicitar um índice de reajuste anual ou uma regra claramente formulada; tampouco havia norma de precificação por idade e os contratos podiam conter cláusulas de reajustes aplicáveis para septuagenários e octogenários, muitas vezes sem estabelecer os percentuais em cada passagem de faixa etária. Diante de reajustes mais altos do que o limite fixado pelo Governo, a tendência dos portadores de planos antigos nãoadaptados era de demandar que o reajuste fosse limitado ao percentual máximo admitido oficialmente. Ainda há demandas com esta origem.

Por isso, muitas das demandas são originadas desses contratos antigos nãoadaptados. Com a Lei 9.656 e as normas subsequentes editadas pela Conselho Nacional de Saúde Suplementar, CONSU, muitos desses fatores originadores de demandas foram equacionados. A Lei não vedou a faculdade de estabelecer preços de acordo com a idade nem definiu as faixas, mas no seu Art. 15, determinou que essa faculdade somente fosse exercida se os contratos explicitassem as faixas e os respectivos preços, portanto também os índices de reajuste em cada passagem de faixa etária.

Art. 15. A variação das contraprestações pecuniárias estabelecidas nos contratos de produtos de que tratam o inciso I e o $\S 1$ o do art. 
1o desta Lei, em razão da idade do consumidor, somente poderá ocorrer caso estejam previstas no contrato inicial as faixas etárias e os percentuais de reajustes incidentes em cada uma delas, conforme normas expedidas pela ANS, ressalvado o disposto no art. 35-E. (Redação dada pela Medida Provisória no 2.177-44, de 2001).

A Resolução CONSU 08 fixou sete faixas etárias, admitindo o último reajustes aos 70 anos de idade. Esse dispositivo não contrariava nenhuma norma legal e sua adoção nos contratos era, portanto, ato jurídico perfeito, inalcançável por normas posteriores.

A superveniência do Estatuto do Idoso, Lei 10.741/2003, com eficácia a partir de 1 de janeiro de 2004, em seu Art. 15, §3º, vedou discriminar idosos nos planos de saúde pela cobrança de valores diferenciados em razão da idade - verbis:

Artigo 15, § $3^{\circ}$. É vedada a discriminação do idoso nos planos de saúde pela cobrança de valores diferenciados em razão da idade.

Em vista desse dispositivo, a ANS alterou a Resolução CONSU 08, para adotar dez faixas etárias, a última começando aos 59 anos de idade.

Em razão dessas mudanças legais, sobrevivem contratos pactuados sob três diferentes vigências normativas: contratos antigos não-adaptados anteriores a 1099, contratos pactuados entre 1999 e 2003; e contratos pactuados na vigência do Estatuto do Idoso, a partir de 2004. Considerando que as cláusulas não tenham ferido nenhuma norma legal, sendo, portanto, atos jurídicos perfeitos, os reajustes por mudança de faixa etária seguiriam três dispositivos diferentes, de acordo com a data de pactuação do contrato. Os antigos podem ter os reajustes explicitados nos contratos, sem limites de idade; os pactuados na vigência da Resolução 08 do CONSU, podem ter reajustes aos 60 e aos 70 anos de idade; os pactuados na vigência do Estatuto do Idoso terão seu último reajuste por mudança de faixa etária aos 59 anos de idade. Essa questão ainda está pendente de decisão pelo Judiciário.

Compreende-se, portanto, a existência de tantas demandas relativas aos reajustes por faixa etária.

A Lei n. 9.656 determinou a cobertura de todas as doenças listadas na CID-10, e previu explicitamente exclusões ligadas a tratamentos experimentais, com fins estéticos, inseminação artificial, tratamentos para rejuvenescimento ou emagrecimento para fins estéticos, medicamentos importados não nacionalizados, medicamentos para tratamento domiciliar, fornecimento de órteses e próteses não lidadas ao ato cirúrgico, tratamentos ilícitos ou antiéticos (Art. 10 e alíneas).

Cada uma dessa exclusões de cobertura, com a possível exceção dos ilícitos ou antiéticos, enseja demandas judiciais.

O Gráfico 1 ilustra a distribuição dos principais motivadores de demandas de uma amostra de grandes operadoras, relativas aos processos cadastrados ou 
encerrados entre 2012 e 2018 em todo o País. Exclusões contratuais era o tema de $32,7 \%$ dos casos encerrados e $25,4 \%$ dos novos casos cadastrados. Caiu, portanto, o estoque pendente de decisão relativo a esse tipo de demanda. O segundo item mais demandado é relativo aos reajustes anuais e por faixa etária, com 12,5\% dos encerrados e $28,5 \%$ dos novos casos.

Nota-se uma mudança no perfil das demandas - queda nas demandas relativas a exclusões e intensificação das demandas por reajustes, que se tornaram dominantes. Esse movimento pode ser atribuído a melhorias nos processos das autorizações e aos elevados aumentos das despesas com a assistência à saúde nesse período, o que levaram a altos reajustes das mensalidades, tanto dos planos individuais quanto os coletivos.

Gráfico 1. Demandas em face de planos de saúde - principais causas - amostra operadoras $2011-2018$.

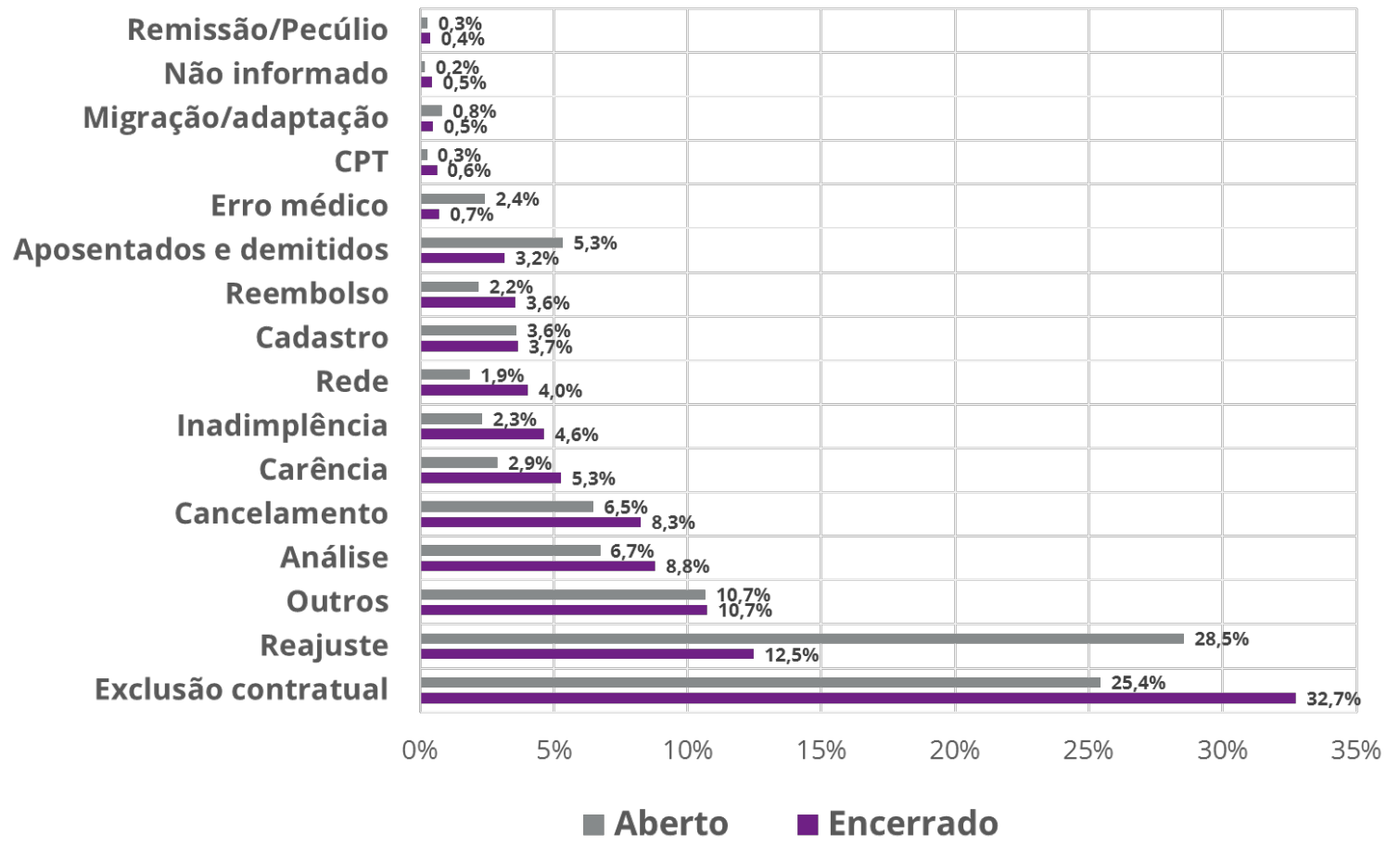

A base de dados é composta por 295 mil novos processos cadastrados entre 2012 e 2018 e 238 mil encerrados nesse mesmo período. O estoque em tramitação ao final de 2018 era de 82 mil ações. O Gráfico 2 mostra a evolução anual dos processos cadastrados anualmente e dos encerrados nesse período. Observa-se claramente que o ritmo de encerramento superou o de cadastramento entre 2012 e 2017. Em 2018, caiu o número de cadastramentos e mais ainda o de processos encerrados. A redução do número de processos se deve às diversas ações judiciais em andamento no STJ afetadas como casos repetitivos, entre elas o reajuste por faixa etária, a (im)possibilidade de permanência no plano de saúde da empresa de demitido sem justa causa que necessita de tratamento continuado, a questão do Rol de 
Procedimentos se é taxativo ou exemplificativo. Também colaboram no mesmo sentido as iniciativas de solução de conflitos extrajudiciais, em câmaras de mediação ou conciliação.

Gráfico 2. Demandas cadastradas e encerradas em face de planos de saúde. 2011 2018.

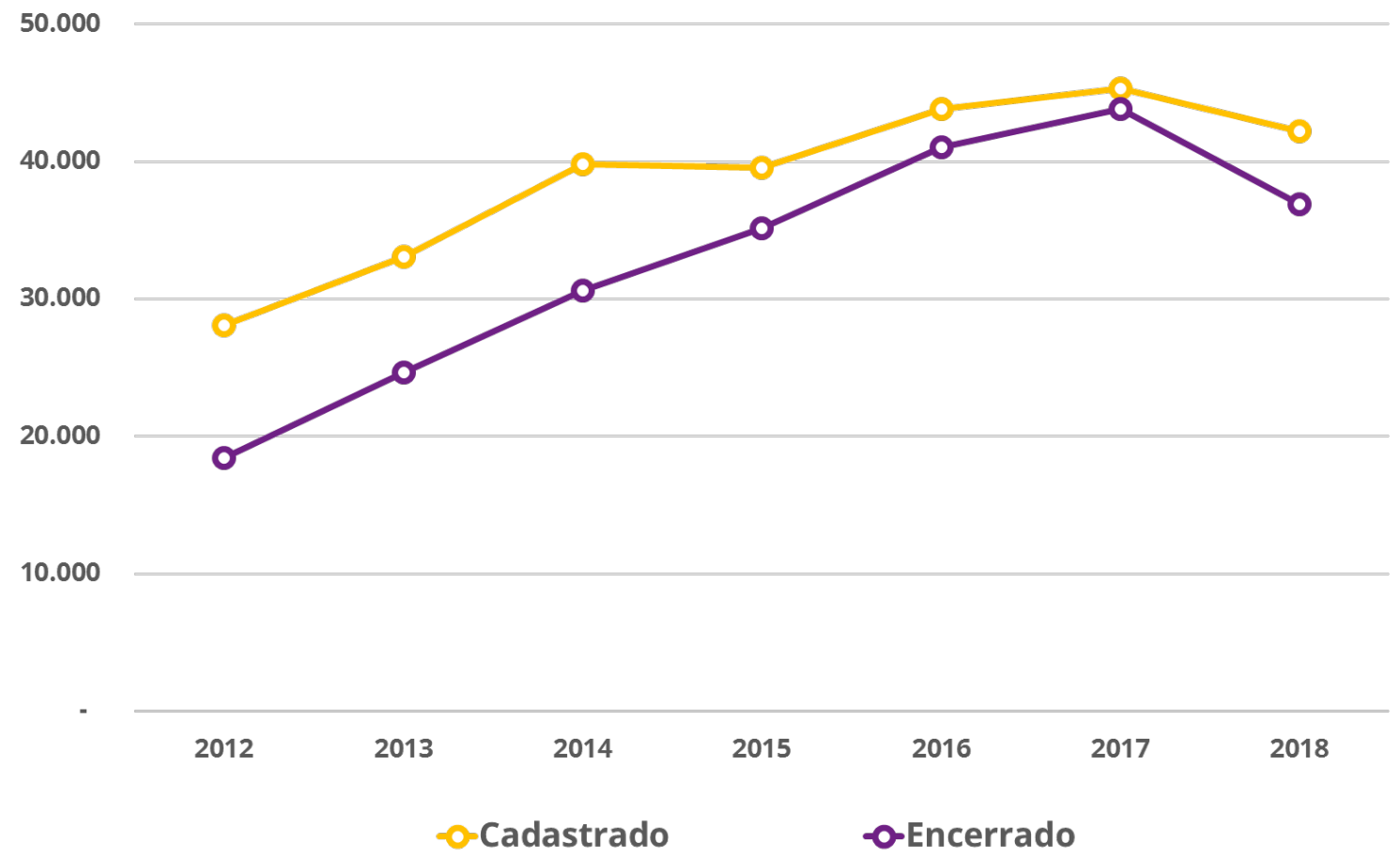

O tempo médio de tramitação dos processos encerrados desta amostra, entre 2012 e 2018, caiu de um ano e dez meses para um ano e sete meses, redução de 13,6\%. A redução foi particularmente acelerada em Pernambuco, que teve queda de $38,5 \%$, e na Bahia, de $42,9 \%$.

Nessa amostra, a propensão a litigar no período cresceu intensamente no Nordeste enquanto nas outras regiões cresceu suavemente até 2017 e caiu em 2018 (Gráfico 3). 
Gráfico 3. Propensão a litigar por Região (proporção do número de processos cadastrados anualmente pelo número médio de beneficiários do ano)

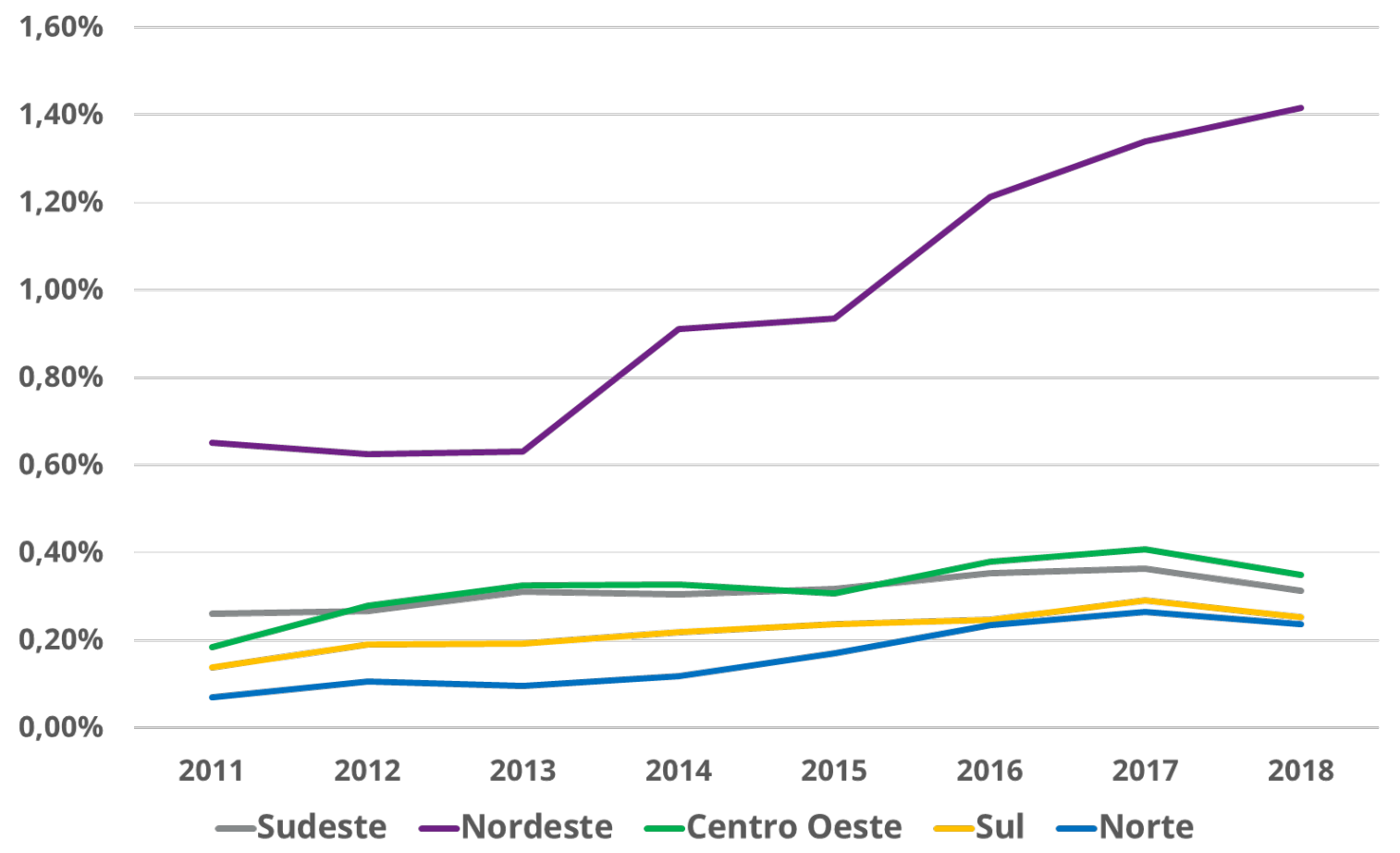

Esses dados mostram o esforço que o Judiciário vem fazendo no sentido de dar maior celeridade à solução das demandas. Segundo Justiça em Números de 2019, em 2014, em todo o Judiciário do Brasil, foram cadastradas 29,0 milhões de demandas não criminais e encerradas 28,4 milhões; quatro anos depois, em 2018, foram cadastradas 28,0 milhões, ou 3,4\% a menos, e encerradas 31,9 milhões, ou $13,9 \%$ a mais. Esse resultado promissor se deve em parte à maior adoção de mecanismos extrajudiciais de solução de conflitos e à migração para processos eletrônicos ${ }^{8}$ que contribuiu para acelerar a tramitação das ações.

Cabe ainda mencionar outros importantes aspectos da saúde suplementar que motivam demandas judiciais. O setor é regulado, as regras mudam com frequência e nem sempre permitem uma discriminação clara dos casos concretos entre o direito e o não-direito. Ou seja, dada a inevitável generalidade da norma, haverá sempre muitos casos concretos que cairão no que se convenciona denominar de zona cinzenta. Essa é a área típica de atuação do Judiciário e a sentença, nesses casos, pode ou deve sopesar princípios constitucionais do valor supremo da vida, do direito à saúde, da dignidade da pessoa humana.

A prestação dos serviços de assistência à saúde é complexa, com uma longa cadeia de valor que vai desde a indústria supridora de equipamentos, materiais,

\footnotetext{
${ }^{8} \mathrm{CNJ}$, Justiça em Números, de 2019. Segundo essa publicação, 13\% dos processos eram eletrônicos em 2010 e 83,4\% em 2018, um notável progresso.
} 
insumos e medicamentos, passando por uma vasta gama de profissionais de saúde, prestadores que se organizam em clínicas, laboratórios e hospitais. São parte essencial dessa longa cadeia os próprios beneficiários e as empresas que contratam planos para seus colaboradores. Entre todos eles estabelecem-se relações comerciais contratuais, algumas reguladas pelo ANS. Nos últimos cinco anos, o elevado crescimento das despesas com assistência à saúde e a prolongada recessão econômica estressou essas relações. Diante do persistente desemprego e da queda nas rendas, o acesso aos serviços de saúde ficou mais difícil, inclusive no setor público, ao tempo em que a procura pode ter se exacerbado em razão de o estresse trazido pela situação econômica do País reduzir a imunidade. Diante dessas dificuldades, as pessoas viram no Judiciário o caminho mais fácil e rápido para conseguir acesso aos serviços de saúde, públicos e privados.

\section{CONSEQUÊNCIAS DA JUDICIALIZAÇÃO}

Demandar na Justiça é direito de todos; demandar quando direitos são desrespeitados e as partes não alcançam o acerto fora do Judiciário é o caminho que resta para assegurar o direito. Porém demandar sem motivo justo não é correto.

As ações judiciais têm custos que são arcados por toda a sociedade, custos esses que constituem apenas uma, mas muito importante, de suas consequências econômicas.

É notório que a grande maioria das demandas em saúde são decididas em favor do demandante. Segundo o citado relatório de pesquisa do INSPER para o CNJ mostra que $74,68 \%$ das demandas foram julgadas procedentes e outras $10,39 \%$ parcialmente procedentes. Números semelhantes são reiteradamente reportados na imprensa.

Essa alta taxa de sucesso, também mencionada pelo $\mathrm{TCU},{ }^{9}$ é poderoso estimulador de novas demanda. Na quase certeza de ter sua demanda atendida, o que frearia a demanda por novas ações? Portanto, a alta taxa de deferimento das demandas é poderoso estimulador de novas ações, aprofundando os custos sociais.

Estaria essa taxa refletindo um alto percentual de negativas do direito aos serviços de assistência à saúde pública ou à cobertura pelo plano de saúde ou ainda a recusas sistemáticas das partes de solucionarem a questão extrajudicialmente?

A alta expectativa de ter sua demanda atendida inibe o demandante de transacionar com sua operadora; a operadora, por sua vez, no entendimento de que não assiste direito ao demandante, teme que acatar a demanda abra precedente $\mathrm{e}$ se veja forçada a todos os casos desse tipo, o que equivaleria a incorporar o procedimento na cobertura, sem que tenha havido a necessária contribuição. Por vezes, o demandante sequer apresenta previamente sua demanda à operadora. A

${ }_{9}^{9}$ TCU - Relatório de Auditoria Operacional na Saúde Pública. 16 de agosto de 2017. 
maioria dos casos que são previamente submetidos à operadora são resolvidos nessa etapa. ${ }^{10}$

Embora não se tenham dados consolidados relativos à proporção das demandas que pleiteiam uma vantagem individual não incluída nas normas nem no contrato, há evidentes casos que podem ser enquadrados nessa situação. Na saúde pública, as demandas por medicamentos não incluídos na lista oficial, não nacionalizados, sem registro na ANVISA ou ainda sem a evidência de efetividade ou demonstração de inexistência de efeitos colaterais negativos severos. Isso também acontece entre beneficiários de planos de saúde (veja-se, por exemplo, o notório caso recente da pílula do câncer, a fosfoetanolamina, que não tinha evidência de efetividade, nem demonstração de que não faria mal, nem registro na ANVISA).

Na saúde suplementar, há demandas para assegurar determinada marca de dispositivos médicos implantáveis, como nos casos muito conhecidos da máfia das próteses, ${ }^{11}$ ou solicitam deferimento para a realização de implante de dispositivo médico sem necessidade, o que poderia ser tipificado como crime de lesão corporal. Também eram comuns as demandas por cirurgias bariátricas, normalmente originadas de poucos advogados ou escritórios, que alegavam risco iminente à vida se o procedimento não fosse realizado imediatamente. A cirurgia pode ser a indicação adequada, mas sua realização deve seguir as diretrizes de utilização estabelecidas no Rol de Procedimentos da ANS, que exige demonstração de tentativas de perda de peso por métodos convencionais por pelo menos dois anos. Ademais, cirurgia bariátrica quase nunca é caso urgência ou emergência. ${ }^{12}$

Podem-se ainda enquadrar nessa categoria de busca por vantagem individual as demandas relativas à inseminação artificial, medicamentos não registrados na ANVISA, procedimentos experimentais ou com finalidade estética não reparadora, todos excluídos expressamente pela Lei n. 9.656. Por terem sido explicitamente excluídos da Lei, não compuseram os custos estimados na Nota Técnica de Registro de Produto, e a autorização judicial para sua realização pode desequilibrar econômica e financeiramente a operadora.

Como mostrado acima, nos anos recentes observou-se um crescimento acelerado das demandas relativas aos reajustes, que se tornaram predominantes, à frente das demandas por coberturas. Dizem respeito à alegada abusividade do percentual de reajuste, tanto o anual quanto por mudança de faixa etária ou à aplicação de reajustes em idades acima dos 60 anos, sob a alegação de contrariar o Estatuto do Idoso.

\footnotetext{
${ }^{10}$ Pesquisa Ibope de 2019, em parceria com o IESS, mostrou que 91\% das solicitações de autorização foram deferidas pela operadora e outra fração importante $(7 \%)$ recebeu explicações ou orientações e cerca de dois por cento precisaram recorrer a outros expedientes.

${ }^{11}$ Denunciada em rede nacional de TV, no Fantástico em janeiro de 2015. Registre-se que essa prática é vedada por Resolução do CFM.

12 Veja-se a respeito, os estudos do IESS publicados em "Pareceres Técnico Científicos V. 1" de autoria de L. Bahia e Denizar Vianna, da UERJ, e de Patricia Medina e Otavio Clark, do Instituto Evidências - Credibilidade Científica.
} 
Primeiro, os reajustes anuais. As regras para este reajuste variam por tipo de contratação. Na individual e familiar, o reajuste é determinado pelo Governo e se aplica a todos os contratos regulados (isto é, contratados a partir de 1999 ou anteriores, mas adaptados à regulação). Aos contratos antigos não-adaptados aplica-se o disposto no contrato; se o contrato nada dispõe a respeito, aplica-se o reajuste determinado pela ANS; para alguns antigos não-adaptados foram celebrados, no início dos anos 2000, Termos de Ajuste de Conduta com regra própria para os reajustes. Os contratos coletivos com mais de trinta vidas têm seus reajustes definidos por livre negociação entre a operadora e a entidade contratante, mas respeitando o que tiver sido clausulado no contrato. Os contratos com menos de 30 vidas que estejam na mesma operadora devem ser considerados como um pool de risco, com reajuste único para todos, definido pela variação média da despesa per capita desse pool. Compreende-se que a variação das despesas per capita apresenta uma grande dispersão entre os diferentes contratantes e que essa dispersão enseja demandas judiciais. Altos percentuais de reajuste são necessários frente ao igualmente alto crescimento das despesas per capita. Caso o reajuste não seja equivalente à variação da despesa, e essa prática seja reiterada, notar-se-á crescente desequilíbrio econômico-financeiro, que poderá levar a operadora à insolvência.

Segundo, as variações por mudança de faixa etária. Nesse tema, observam-se dois tipos de alegação - abusividade do percentual aplicado na passagem dos 58 para os 59 anos de idade e impossibilidade de aplicação para quem já completou 60 ou mais anos de idade, independente da época de pactuação do contrato, em razão do Estatuto do Idoso.

Na questão da abusividade, deve-se considerar que percentuais altos decorrem da elevada variação das despesas per capita na passagem da penúltima para a última faixa etária, cabendo à operadora a demonstração dessa variação perante o julgador nos casos concretos. ${ }^{13}$ Virtualmente todas as estatísticas brasileiras e internacionais mostram que nessa passagem de faixa etária a despesa per capita dobra - um simples fato da vida. Portanto, o reajuste será necessariamente alto. Mas que percentual alto poderia ser considerado abusivo?

A regulamentação diz que o preço da última faixa pode, no máximo, ser seis vezes maior do que o preço da primeira faixa e que a variação percentual da sétima para a décima não pode ser maior do que a variação da primeira para a sétima. Essa segunda condição foi introduzida pela Resolução Normativa 63/03 da ANS para evitar reajustes baixos nas mudanças das faixas etárias anteriores, concentrando grande parte do reajuste na última faixa etária. Por isso, em contratos celebrados até o final de 2003 podem-se observar reajustes bem altos, sem contrariar nenhuma norma legal. Essa prática é usualmente entendida como contrária aos interesses dos consumidores e objetivaria a expulsão dos idosos de seus planos de saúde. Do

\footnotetext{
${ }^{13}$ A demonstração atuarial da necessidade do reajuste na passagem dos 58 para os 59 anos de idade consta da Nota Técnica de Registro de Produto, NTRP, que deve ser aprovada pela ANS para que o plano possa ser comercializado.
} 
ponto de vista estritamente técnico e financeiro, essa prática é benéfica aos beneficiários. É fácil de entender. O preço da última faixa é, por Resolução do CONSU ou da ANS, seis vezes o da primeira, independente da trajetória dos preços nas faixas intermediárias. Quanto menores os reajustes nas faixas intermediárias menor será o desembolso acumulado como mensalidade. O beneficiário disciplinado que investisse o valor a menor de cada mensalidade nas faixas anteriores à última poderia acumular uma poupança que lhe permitiria pagar dezenas de mensalidades. ${ }^{14} \mathrm{O}$ que se pode alegar é a falta de educação financeira da maioria da população brasileira, inclusive a de beneficiários de planos de saúde. Parece que a medida, nesse caso, deveria ser a educação financeira do consumidor e não a ilusão de proteção por norma que contraria o seu interesse objetivo, ainda que não bem percebido.

Essa realidade sugere que se linearizem os reajustes entre a sétima e décima faixas etárias, isto é, que se aplique o mesmo percentual em cada mudança. Essa regra não existe, mas nada impede que seja adotado. Aplicando-se as normas de precificação vigentes, o percentual uniforme seria de 34,8\%. Reconheça-se, trata-se de um percentual alto. Mas poderia ser considerado abusivo, se resulta da estrita aplicação das normas?

Outras demandas questionam a aplicação de reajustes depois dos 60 anos de idade nos contratos celebrados antes de sua vigência, o que seria vedado pelo Estatuto do Idoso. Contratos pactuados na sua vigência seguem estritamente essa regra e não têm reajustes depois dos 60 anos de idade. Porém, contratos celebrados antes de sua vigência podiam ter reajuste ao completarem 60 e de novo aos 70 anos. Esse dispositivo contratual não contrariava as normas da época da celebração, sendo, portanto, um ato jurídico perfeito. A Constituição Brasileira preserva o ato jurídico perfeito, o direito adquirido e a coisa transitada em julgado. No entanto, nas primeiras e segundas instâncias da Justiça observam-se decisões pela não aplicação dos dispositivos desse Estatuto aos contratos celebrados antes de sua vigência, bem como sentenças em direção oposta. A questão ainda está pendente de decisão pelo Judiciário.

Decisão que vede a aplicação dos reajustes pactuados nos contratos celebrados antes da vigência do Estatuto, nas mudanças de faixas etárias depois dos 60 anos de idade, terá consequências econômicas e financeiras sobre as operadoras. As avaliações atuariais, demonstradas na Nota Técnica de Registro de Produtos e aprovadas pela ANS, foram feitas na hipótese de efetiva aplicação nas mudanças de faixas etárias estabelecidas nas normas, aos 60 e aos 70 anos de idade. A não aplicação causará perdas financeiras relevantes para as operadoras. ${ }^{15}$

Para concluir essa seção citam-se outras importantes consequências econômicas das decisões judiciais relativas à saúde, particularmente a pública, apontadas pelo Relatório do TCU. Entre elas a realocação emergencial de recursos dos entes

\footnotetext{
${ }^{14}$ Martins, C. B. Reajuste por faixa etária, uma abordagem financeira. IESS, março 2009

${ }^{15}$ Estimativas de impacto podem ser encontradas em: Parecer Técnico Atuarial. FIPECAFI \& MILLIMAN, 2009, apresentado III Congresso Jurídico da Saúde Suplementar de SP D.
} 
federados reduzindo sua eficiência, "inviabilizando uma racionalidade sistêmica no acesso a ações e serviços de saúde"; a descontinuidade de tratamentos de pacientes regulares dadas as limitações de capacidade de atendimento; preços mais altos dos materiais e medicamentos adquiridos emergencialmente, portanto sem concorrência. As implicações vão além: elitizam o acesso à saúde, pois os altos custos das demandas afastam os mais pobres; as decisões desconsideram custoefetividade, pela interpretação da saúde como direito absoluto a quaisquer serviços de saúde, inclusive os adotados em outros países.

Frente a todos esses impactos, interessa desenvolver políticas para conter o crescimento acelerado das ações judiciais. Cabe ressaltar que por serem múltiplos os seus motivadores, não há uma medida única capaz de reverter a tendência de crescimento. Haverá necessidade de um conjunto de ações, entre elas, o aperfeiçoamento das normas reguladoras da saúde, sua melhor sintonia com o momento atual da sociedade, o incentivo aos mecanismos de solução préprocessual de conflitos, a disponibilização e transparência de informações para que todos melhor fundamentem suas decisões.

\section{CONCLUSÃO}

Inúmeros indicadores apontam para o crescimento acelerado do número de ações judiciais em matérias de saúde, pública e privada. Discorreu-se sobre o contexto socioeconômico desse movimento, ficando claro que seus motivadores são múltiplos. Considerando os custos sociais envolvidos, a incerteza jurídica provocada por decisões que não sigam os termos das normas ou cláusulas dos contratos, é de interesse social que esse crescimento acelerado seja contido. Obviamente sem impedir o acesso à Justiça. Em linha com a multiplicidade de motivadores, múltiplas precisarão ser as medidas para conter o ritmo de crescimento. Entre elas encontram-se os mecanismos de conciliação e mediação, os Núcleos de Apoio Técnico ao Judiciário em todos os tribunais estaduais de Justiça, o desenvolvimento de bibliotecas com documentação de evidências das terapias indicadas, bibliotecas com pareceres específicos sobre os principais tipos de demandas, publicações educativas para os consumidores sobre seus direitos e deveres, a melhoria dos processos de autorização por parte das operadoras, canais disponíveis para postagem de demandas por parte dos beneficiários dos planos de saúde com comunicação imediata ao demandado para avaliar possível acerto prévio ao ingresso na Justiça.

A mudança da tendência exige de todos o mais completo envolvimento.

\section{REFERÊNCIAS}

Neto, J. P. G. e Schulze, C. J. Direito à Saúde. Análise à Luz da Judicialização. PA: Verbo Jurídico, 2015. 
L. Bahia e Denizar Vianna, da UERJ; Patricia Medina e Otavio Clark, do Instituto Evidências - "Pareceres Técnico Científicos V. 1" Credibilidade Científica.

Martins, C. B. Reajuste por faixa etária, uma abordagem financeira. IESS, março 2009

Parecer Técnico Atuarial. FIPECAFI \& MILLIMAN, 2009, apresentado III Congresso Jurídico da Saúde Suplementar de SP D. 